literature showed that CPTA Results can vary considerably depending on the clinical setting from $6.6 \%$ for patients seen in $\mathrm{A}$ and $\mathrm{E}$, to up to $31 \%$ for patients admitted in General Medicine with mean positive yield of $18.8 \%$. The documentation of pre-test probability was also poor (between $0 \%$ and 24\%). Results from UK teaching and non-teaching hospitals were similar.

Conclusions Our regional clinical audit showed that our positive yield is lower than the recommended standards. We made good use of d-dimer testing when $\mathrm{PE}$ was suspected in patients with high pre-test probability. Adherence to current guidelines could increase the diagnostic yield and reduce costs and risks associated with CTPA scans. Extrapolated to a larger scale, this would translate into significant reduction in costs and risks associated with radiation and contrast exposure. Most of the reported clinical audits from UK hospitals revealed acceptable CTPA positive rates.

\begin{tabular}{lll}
\multicolumn{2}{l}{ Abstract P182 Table 1} & Audit results \\
\hline & d-dimers & Positive CTPA result \\
\hline \multirow{2}{*}{ Low Wells score ( $\mathrm{n}=183)$} & Tested positive: $92(50 \%)$ & 11 \\
& Not tested: $88(49 \%)$ & 6 \\
& Negative: $3(0.2 \%)$ & 0 \\
& & \\
High Wells score $(\mathrm{n}=53)$ & Tested positive: $17(32 \%)$ & 4 \\
& Not tested: $36(68 \%)$ & 13 \\
& Negative: 0 & - \\
\hline Total=236 34 (14\%) &
\end{tabular}

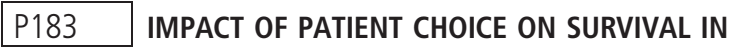 PATIENTS WITH CHRONIC THROMBOEMBOLIC PULMONARY HYPERTENSION OFFERED PULMONARY ENDARTERECTOMY}

${ }^{1}$ SR Quadery, ${ }^{2} \mathrm{AJ}$ Swift, ${ }^{1} \mathrm{C}$ Billings, ${ }^{2} \mathrm{AAR}$ Thompson, ${ }^{1} \mathrm{CA}$ Elliot, ${ }^{1} \mathrm{~J}$ Hurdman, ${ }^{1} \mathrm{~S}$ Garrod, ${ }^{1} \mathrm{~A}$ Charalampopolous, ${ }^{2}$ Sabroe, I Armstrong, ${ }^{1} \mathrm{~N}$ Hamilton, 'P Sephton, ${ }^{1}$ RA Lewis, ${ }^{1} \mathrm{P}$ Prasannan, ${ }^{3} \mathrm{DP}$ Jenkins, ${ }^{3} \mathrm{~J}$ Pepke-Zaba, ${ }^{3} \mathrm{~N}$ Screaton, ${ }^{2} \mathrm{~A}$ Lawrie, ${ }^{1} \mathrm{CS}$ Johns, ${ }^{1} \mathrm{~S}$ Rajaram, ${ }^{1} \mathrm{C}$ Hill, ${ }^{2} \mathrm{JM}$ Wild, ${ }^{1} \mathrm{R}$ Condliffe, ${ }^{1} \mathrm{DG}$ Kiely. ${ }^{1}$ Sheffield Teaching Hospitals NHS Foundation Trust, Sheffield, UK; ${ }^{2}$ University Of Sheffield, Sheffield, UK; ${ }^{3}$ Papworth Hospital NHS Foundation Trust, Cambridge, UK

\subsection{6/thoraxjnl-2017-210983.325}

Introduction Chronic thromboembolic pulmonary hypertension (CTEPH) is potentially curable by pulmonary endarterectomy (PEA). Despite this a significant proportion of patients offered PEA decline surgery.

Objective To compare long term survival and prognostic indicators in patients with technically operable CTEPH who underwent PEA and those who declined surgery.

Methods Data were collected for consecutive, treatment-naïve patients diagnosed with CTEPH between 2001 and 2014 identified from the ASPIRE-pulmonary-hypertension-registry.

Results Of 588 patients with CTEPH, 368 patients were offered surgery. Seventy six percent $(n=281)$ underwent PEA, $20 \%(n=72)$ declined surgery and $4 \%(n=15)$ were planned to undergo surgery. Five year survival was superior in patients undergoing PEA at $83 \%$ compared to patients who declined surgery at $56 \% \quad(p=0.001$, log-rank test $)$. In patients who were offered surgery, mixed venous oxygen saturation $\left(\mathrm{SvO}_{2}\right)$ $(p=0.003)$, gas transfer (DLco) $(p=0.042)$, history of coronary artery disease $(\mathrm{p}=0.031)$ and patient choice (declining surgery) $(\mathrm{p}<0.001)$ were independent predictors of mortality. For patients who declined surgery a median threshold of DLco $62 \%$, right atrial pressure $11 \mathrm{mmHg}$, and $\mathrm{SvO}_{2} 62 \%$ the positive and negative predictive values for 3 year survival were $31 \%$ and $100 \%, 32 \%$ and $95 \%$ and $30 \%$ and $97 \%$, respectively.

Conclusion In a cohort of consecutive patients with CTEPH the long-term survival of patients undergoing PEA is excellent and superior to patients declining surgery and strongly favours surgical intervention in eligible patients. More work is required to understand factors influencing decision making in CTEPH and to ensure that patients are counselled and supported to make informed decisions.

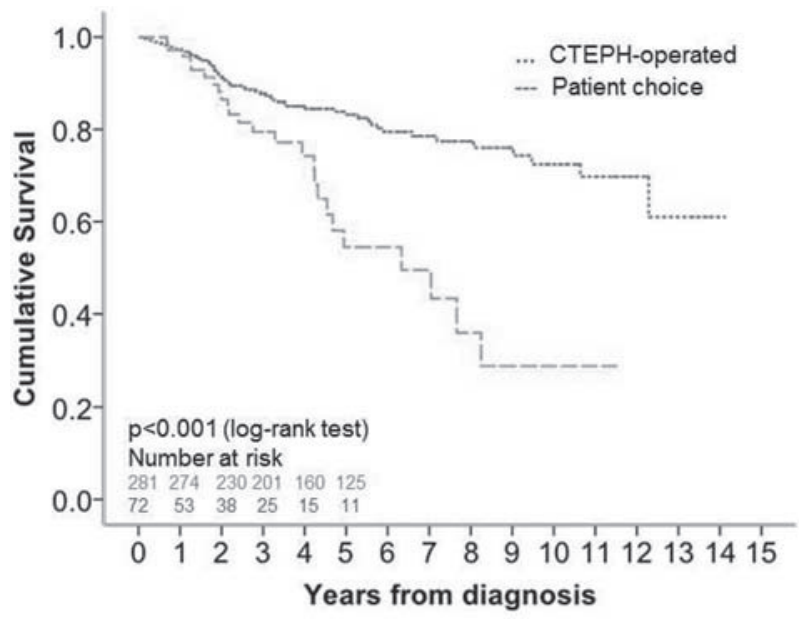

Abstract P183 Figure 1

\section{P184 AGE SHOULD NOT BE A BARRIER TO PULMONARY ENDARTERECTOMY IN CAREFULLY SELECTED PATIENTS}

M Newnham, J Hernandez-Sanchez, J Dunning, C Ng, S Tsui, K Bunclark, K Sheares, D Taboada, M Toshner, J Pepke-Zaba, D Jenkins, J Cannon. Papworth Hospital, Cambridge, UK

\subsection{6/thoraxjnl-2017-210983.326}

Introduction We previously reported that hospital survival in patients over 70 years undergoing pulmonary endarterectomy (PEA) was comparable to those under 70, albeit with longer hospital and intensive care unit (ICU) stays. ${ }^{1}$ Octogenarians have acceptable morbidity and mortality outcomes following cardiac surgery. We aimed to assess if this also applies to PEA surgery.

Methods Consecutive patients undergoing PEA for chronic thromboembolic pulmonary hypertension (CTEPH) from June 2006 to August 2016 at the National referral centre for PEA were included in a retrospective analysis. The cohort was dichotomized into over and under 80 years according to age at surgery. Pre-operative baseline and post-operative 36 month follow-up data were recorded, with follow-up data included until November 2016.

Results 1152 individuals underwent PEA (1115 under 80 years, 37 over 80 ) during the study period. Baseline and $3-$ 6 month follow up variables and outcomes are summarised in Table 1. Survival is lower in the over 80 group (Log-rank test, $p=0.002$ ), but is no different from an age and sex 


\begin{tabular}{|c|c|c|c|c|c|c|}
\hline \multirow[b]{3}{*}{$\mathbf{n}$} & \multicolumn{3}{|c|}{ Baseline } & \multicolumn{3}{|c|}{ Follow-up } \\
\hline & Under $\mathbf{8 0}$ & Over 80 & P-value ${ }^{a}$ & Under $\mathbf{8 0}$ & Over 80 & P-valuea \\
\hline & 1115 & 37 & & & & \\
\hline Age [median (IQR)] & $61(22)$ & $81(2)$ & & & & \\
\hline Gender [female (\%)] & 46 & 46 & NS & & & \\
\hline NYHA class $[1 / 2 / 3 / 4(\%)]^{b}$ & $0 / 14 / 73 / 13$ & $0 / 3 / 70 / 26$ & NS & $28 / 47 / 23 / 1$ & $22 / 40 / 33 / 4$ & NS \\
\hline 6mwd [metres; median (IQR)] & $295(190)$ & $227(229)$ & NS & $363(157)$ & 284(101) & 0.001 \\
\hline mPAP [mmHg; median (IQR)] & $45(15)$ & $42(12)$ & NS & $25(13)$ & $28(12)$ & NS \\
\hline PVR [dynes.s.cm ${ }^{-5}$; median (IQR)] & $666(479)$ & $743(462)$ & NS & $235(212)$ & $297(294)$ & NS \\
\hline $\mathrm{Cl}$ [Lmin/m²; median (IQR)] & $2.18(0.84)$ & $2.06(1.05)$ & NS & $2.28(0.69)$ & $2.26(0.72)$ & NS \\
\hline $\begin{array}{l}\text { CAMPHOR: [median (IQR)] } \\
\text { Symptoms } \\
\text { Activity } \\
\text { Quality of life }\end{array}$ & $\begin{array}{l}13(10) \\
11(9) \\
11(11)\end{array}$ & $\begin{array}{l}12(9) \\
14(8) \\
11(11)\end{array}$ & $\begin{array}{l}\text { NS } \\
\text { NS } \\
\text { NS }\end{array}$ & $\begin{array}{l}4(8) \\
6(9) \\
4(10)\end{array}$ & $\begin{array}{l}4(7) \\
9(6) \\
6(8)\end{array}$ & $\begin{array}{l}\text { NS } \\
\text { NS } \\
\text { NS }\end{array}$ \\
\hline Type of surgical disease ${ }^{\circ}[1 / 2 / 3 / 4(\%)]$ & $14 / 58 / 26 / 3$ & $14 / 59 / 27 / 0$ & NS & & & \\
\hline Bypass time [min; median (IQR)] & $323(65)$ & $305(51)$ & 0.002 & & & \\
\hline Arrest time [min; median (IQR)] & $37(15)$ & $33(13)$ & NS & & & \\
\hline $\begin{array}{l}\text { Length of stay [days; median (IQR)] } \\
\text { Intensive care unit } \\
\text { Total hospital }\end{array}$ & $\begin{array}{c}4(3) \\
14(10)\end{array}$ & $\begin{array}{l}5(4.5) \\
19(7)\end{array}$ & $\begin{array}{l}\text { NS } \\
0.001\end{array}$ & & & \\
\hline $\begin{array}{l}\text { Concomitant surgery: Total [n (\%)] } \\
\text { CABG } \\
\text { PFOIASD } \\
\text { MVR } \\
\text { AVR }\end{array}$ & $\begin{array}{c}129(11) \\
76 \\
34 \\
12 \\
4\end{array}$ & $\begin{array}{c}10(26) \\
7 \\
1 \\
0 \\
2\end{array}$ & NS & & & \\
\hline In-hospital mortality [n (\%)] & $45(4)$ & $3(8)$ & NS & & & \\
\hline $\begin{array}{l}\text { Survival [\%] } \\
1 \text { year } \\
3 \text { years } \\
5 \text { years }\end{array}$ & & & & $\begin{array}{l}91.8 \\
88.2 \\
84.4\end{array}$ & $\begin{array}{l}83.5 \\
76.4 \\
69.4\end{array}$ & 0.002 \\
\hline
\end{tabular}

Baseline and follow-up variables and outcomes subdivided by age cohorts. The follow-up time for NYHA, 6MWT, haemodynamics and CAMPHOR score was 3-6 months. ap-values were calculated using Chi-squared test or Fisher's exact test for categorical data, Wilcoxon rank-sum test for continuous data and Log-rank test for survival data. A Bonferroni adjusted significance threshold of $<0.002$ was used. Significant P-values are highlighted in bold. ${ }^{\mathrm{b}}$ Total percentage may not add up to loo due to rounding ${ }^{\mathrm{C} J a m i e s o n}$ classification. NYHA, New York Heart Association; 6MWT, 6 minute walking test; mPAP, mean pulmonary arterial pressure; PVR, pulmonary vascular resistance; Cl, cardiac index; CAMPHOR, Cambridge Pulmonary Hypertension Outcome Review score; IQR, interquartile range; CABG, coronary artery bypass graft; PFO!ASD, patent foramen ovale I atrial septal defect; MVR, mitral valve replacement; AVR, aortic valve replacement; NS, not significant.

matched UK reference population $(p=0.5)$ (Office of National Statistics). The hospital length of stay was longer in those over 80 (median: 19 vs. 14 days; $\mathrm{p}=0.001$ ), however, there was no difference in NYHA class, haemodynamics, type of surgical disease, CAMPHOR score or ICU length of stay between the two age groups. There were more concomitant cardiac surgical procedures in the over 80 group $(26 \%$ vs $11 \%, \mathrm{p}=0.006)$, although this was not statistically significant when accounting for multiple testing.

Conclusions We found similar outcomes in patients under and over 80 years old undergoing PEA, except for a prolonged hospital length of stay in those over 80 . Whilst survival is reduced in the over 80 group compared to the under 80 , it is no different to the age-sex matched population. Age alone should not be a contraindication for PEA and individuals with suspected CTEPH should be referred for specialist evaluation.

\section{REFERENCE}

1. Berman M, Hardman G, Sharples L, Pepke-Zaba J, Sheares K, Tsui S, et al. Pulmonary endarterectomy: Outcomes in patients aged $\geq 70$. Eur I Cardiothorac Surg 2012;41(6):154-60.

\section{Biomarkers, imaging and outcomes in COPD}

\section{P185 URINE BIOMARKER PROFILES ASSOCIATED WITH COPD EXACERBATIONS}

${ }^{1} \mathrm{~A}$ Yousuf, ${ }^{2} \mathrm{G}$ Parekh, ${ }^{2} \mathrm{~L}$ Watson, ${ }^{1} \mathrm{~L}$ George, ${ }^{1} \mathrm{~A}$ Singapuri, ${ }^{1} \mathrm{~V}$ Mistry, ${ }^{2} \mathrm{P}$ Davis, C Brightling. 'NIHR Leicester Biomedical Research Centre- Department of Infection, Inflammation and Immunity. Glenfield Hospital, Leicester, Leicestershire; ${ }^{2}$ Mologic Ltd, Bedford, UK

\subsection{6/thoraxjnl-2017-210983.327}

Introduction COPD exacerbations cause considerable morbidity and mortality. Early identification and appropriate treatment might improve patient outcomes. We sought to determine whether urinary biomarkers are associated with a COPD exacerbation.

Method Urine samples from paired stable and exacerbation visits from 55 subjects were available from the COPD-BEAT study. 50 biomarkers were analysed in each sample at Mologic (Mologic LTD). Biomarkers that fulfilled the criteria i) a 